\title{
Social enrichment during postnatal development induces transgenerational effects on emotional and reproductive behavior in mice
}

\author{
James P. Curley ${ }^{1}$, Stephanie Davidson ${ }^{1}$, Patrick Bateson ${ }^{2}$ and Frances A. Champagne ${ }^{1 *}$ \\ Department of Psychology, Columbia University, New York, NY, USA \\ 2 Sub-Department of Animal Behaviour, Cambridge University, Madingley, Cambridge, UK
}

\section{Edited by:}

Larry J. Young, Emory University

School of Medicine, USA; Yerkes

National Primate Research Center, USA

Reviewed by:

Igor Branchi, Istituto Superiore di

Sanita, Italy

Todd H. Ahern, Emory University, USA

${ }^{*}$ Correspondence:

Frances A. Champagne, Department of

Psychology, Columbia University,

Room 406 Schermerhorn Hall, 1190

Amsterdam Avenue, New York, NY

10027, USA.

e-mail:fac2105@columbia.edu
Across species there is evidence that the quality of the early social environment can have a profound impact on neurobiology and behavior. In the present study we explore the effect of communal rearing conditions (three dams with three litters per cage) during the postnatal period on offspring (F1) and grand-offspring (F2) anxiety-like and maternal behavior in Balb/c mice. Females rearing pups in communal nests exhibited increased levels of postpartum maternal care and communal rearing was found to abolish sex-differences in weaning weights. In adulthood, communally reared offspring were observed to display reduced anxiety-like behavior when placed in a novel environment. When rearing their own offspring under standard conditions, communally reared females demonstrated higher levels of motivation to retrieve pups, built higher quality nests, and exhibited higher levels of postpartum care compared to standard reared females. When exposed to an intruder male, communally reared females were more subordinate and less aggressive. F2 offspring of communally reared females were observed to engage in reduced anxiety-like behavior, have larger litter sizes and an increased frequency of nursing on PND 1. Analysis of neuropeptide receptor levels suggest that a communal rearing environment may exert sustained effects on behavior through modification of oxytocin and vasopressin (V1a) receptor densities. Though Balb-C mice are often considered "sociallyincompetent" and high in anxiety-like behavior, our findings suggest that through enrichment of the postnatal environment, these behavioral and neuroendocrine deficits may be attenuated both within and across generations.

Keywords: communal nesting, maternal care, anxiety, oxytocin, vasopressin, Balb/c

\section{INTRODUCTION}

In mammals, there is typically an intense period of mother-infant interaction during the postnatal period that is essential for growth and development of offspring. However, within and across species, there is certainly evidence for a high degree of variation in the quality of maternal care (Fairbanks, 1989; Insel and Shapiro, 1992; Maestripieri, 2005). Thus, even amongst inbred strains of laboratory rodents, there is within strain variation in particular forms of maternal behavior and in the pattern of mother-infant interaction (Champagne et al., 2003a, 2007) and this variation can also be induced through genetic manipulation of the female (Leckman and Herman, 2002) or through alterations in the prenatal or postnatal environment (Lovic et al., 2001; Smith et al., 2004). In a laboratory environment, the study of the long-term impact of variation in mother-infant interactions has been conducted using a variety of rodent models but provides converging evidence for maternal influence on offspring gene expression, neurobiology and behavior (Fernandez-Teruel et al., 1997; Lehmann and Feldon, 2000; Meaney, 2001).

Experimental evidence for the role of maternal care in shaping offspring development is based primarily on rodent models in which lactating dams are singly housed with their litters throughout the postpartum period. However, within the natural ecology of both mice and rats, it is typical for females to care collectively for pups within a communal nest in which multiple females nurse and interact with offspring (Crowcroft and Rowe, 1963; Mennella et al., 1990; Schultz and Lore, 1993). Thus, even amongst species in which biparental care is not typical, a rearing strategy is employed involving multiple caregivers. The communal rearing paradigm has previously been used to study female kin recognition and reproductive success (Crowcroft and Rowe, 1963; Mennella et al., 1990; Konig, 1994), with more recent studies focusing on the cognitive and behavioral outcomes associated with being reared in a communal nest (Branchi, 2009). Studies of singly vs. communally reared ICR mice suggest that there are significant increases in hippocampal BDNF and cell survival in offspring reared under communal conditions and evidence for increased social competency as indicated by an increased ability for communally reared males to establish and re-establish dominance hierarchies (Branchi et al., 2006a,b; D'Andrea et al., 2007). Significant effects of communal nursing on anxiety-like behavior have been previously demonstrated, with the direction of the effect dependent on the sex, strain and age variation of pups within the nest (Sayler and Salmon, 1971; Branchi et al., 2006b).

In addition to predicting variation in anxiety-like behaviors and neuronal survival, the quality of the early social environment, and in particular the amount of maternal care received, predicts variation in social and reproductive behavior of female offspring (Champagne 
et al., 2003a; Coutellier et al., 2008). Natural variations in licking/ grooming (LG) behavior experienced by female pups during the first postnatal week is a significant predictor of the adult maternal behavior of these offspring (Champagne et al., 2003a). High levels of LG experienced in infancy predicts high LG of females when they are adults and caring for their own offspring, with the converse effect when low levels of LG are experienced early in development. This transmission of maternal behavior from mother to daughter can lead to a transgenerational maternal influence such that grandoffspring are likewise influenced by the variations in maternal behavior experienced by previous generations (Champagne and Meaney, 2007). There is increasing evidence for transgenerational effects of environmental experiences (Anway et al., 2005; Crews et al., 2007; Curley et al., 2008; Arai et al., 2009) and it is hypothesized that this type of inheritance may provide a novel route through which adaptive changes in one generation can be transmitted across generations (Badyaev and Uller, 2009; Russell and Lummaa, 2009).

In the current study, we explored the impact of communal rearing on maternal behavior and anxiety-like responses in female mice. Based on the premise that the communal rearing environment serves as a form of early social enrichment we conducted these studies with $\mathrm{Balb} / \mathrm{c}$ mice, a strain that has previously been demonstrated to exhibit reduced maternal care (Carola et al., 2006; Roy et al., 2007), impaired social recognition and interaction (Brodkin, 2007; Panksepp and Lahvis, 2007), and elevated levels of anxietylike behavior (Priebe et al., 2005), in order to determine the possible ameliorating effects of communal rearing on these behavioral outcomes. Moreover, we examined the impact of standard compared to communal rearing environments on both F1 female offspring, who had experienced the communal environment in infancy, and F2 females, who had never experienced the communal environment but who had been reared by an F1 female from a communal nest. In both F1 and F2 offspring we examined region specific levels of oxytocin and vasopressin (V1a) receptors to ascertain the longterm impact of this environmental variation on neural systems involved in social/reproductive and anxiety-like behaviors. These studies involve a novel approach to the study of environmental regulation of brain and behavior which illustrate the persistence across generations of the quality of the early environment and the developmental shifts that can occur through use of ecologically relevant manipulations in a laboratory setting.

\section{MATERIALS AND METHODS ANIMALS AND ANIMAL HUSBANDRY}

Balb/c mice (Mus musculus) used for these studies were bred in our own facility and were the offspring of mice brought in from commercial breeders. All animals were housed at the Sub-Department of Animal Behaviour at the University of Cambridge in accordance to the UK Home Office regulations. Prior to testing, mice were kept in opaque cages $\left(16.5^{\prime} \times 5^{\prime} \times 5^{\prime}\right)$ with steel wire lids on a reverse 12D:12L light cycle under a constant temperature of $21^{\circ} \mathrm{C}$ and $55 \%$ humidity and provided ad libitum water and food (RM1 E rodent chow diet, Lillico, Surrey, UK). All behavioral observations and tests took place during the dark period of the light cycle under dim red illumination.

To generate the litters used in these studies, 30 adult (day 70) $\mathrm{Balb} / \mathrm{c}$ females were mated with adult Balb/c males over a 2-week period. Mating groups consisted of three females and one male per cage. After the mating period, males were removed from the cage and females were monitored daily. At approximately gestational day 16, females were singly housed with continued daily monitoring for the birth of pups. To generate communal rearing conditions, three females who had given birth within the same $12 \mathrm{~h}$ period were housed together in a large $\left(19^{\prime} \times 10.5^{\prime} \times 6^{\prime}\right)$ Plexiglas cage and were provided with 18-19 foster pups pooled from postparturient females who had likewise given birth within the same $12 \mathrm{~h}$ period. Females rearing pups under standard conditions (in the F0 generation only) were also given foster pups from dams who had given birth within the same $12 \mathrm{~h}$ period and housed in large cages. The use of fostering in this cohort was conducted to remove group differences in the dam's exposure to "own" vs. "other" pups. Thus females in both standard (F0 generation only) and communal conditions were rearing foster pups, and all fostering was done on the day of parturition (PND 0).

Throughout the postpartum period, cages were cleaned each week but litters were otherwise undisturbed. Pups were weaned at PND 28 and housed three/cage in same-sex, same-rearing condition groups in the standard sized cages $\left(16.5^{\prime} \times 5^{\prime} \times 5^{\prime}\right)$. At approximately day 70 female $\mathrm{F} 1$ offspring were mated for 2 weeks as in the F0 generation and all females (F1 communal and standard) reared their own non-fostered pups under standard rearing conditions in standard sized cages. F2 offspring were weaned at PND 28, housed in same-sex, same F1 rearing condition groups, and mated at day 70 . All F2 offspring reared their own non-fostered pups under standard rearing conditions as per the F1 females. Thus there were three generations included in this study: (1) F0 females rearing offspring under standard or communal conditions, (2) F1 offspring who had been reared under standard or communal conditions, and (3) F2 grand-offspring of females rearing offspring under standard or communal conditions (included to determine the transgerenational impact of the varied rearing environment).

\section{EXPERIMENTAL DESIGN}

On PND 0 all litters of F0 females were weighed and counted and a brief test of pup retrieval was conducted prior to fostering. Nine females were assigned to communal rearing (generating 3 communal nests) and 11 females assigned to standard rearing. Females who did not get pregnant, lost their litter on the day of birth or gave birth on a day when their pups could not be fostered to an age-matched litter were discarded from the study. Homecage maternal observations were conducted from PND 1 to PND 6. At PND 6, litters were weighed and counted but were otherwise undisturbed until weaning at PND 28. Individual offspring weights were also measured at PND 35 and day 60. At approximately day 65 , male and female $\mathrm{F} 1$ offspring ( $n=25 / \mathrm{sex} /$ group) were tested in the open-field apparatus. In cases where more than one pup per litter was used (a maximum of 3 pups per sex per litter were included), litter effects were controlled for in the analysis. At day 70, female F1 offspring were mated to generate F2 offspring. Litters of F1 females ( $n=16 /$ rearing condition) were weighed and counted on PND 0 followed by a brief test of pup retrieval and home-cage maternal observations from PND 1 to PND 6. Pups were weighed and counted at PND 6 and on PND 7 the F1 dam was briefly 
removed from the cage to measure lactational aggression. Litters were otherwise undisturbed until weaning at PND 28. Only female F2 offspring were used in the F2 behavioral testing. Assessment of F2 offspring (one to two/litter) proceeded in the same design used with the F1 offspring: open-field testing at day 65, mating at day 70, pup retrieval at PND 0, maternal observations from PND 1 to PND 6, and lactational aggression at PND 7. At total of $n=17 \mathrm{~F} 2$ standard and $n=14 \mathrm{~F} 2$ communal litters were tested and analysis of any potential litter effects was included (though none were found significant). F1 females used for brain analysis were sacrificed on PND 28 immediately prior to weaning their pups (between six and eight females per group per receptor type). All F2 females and litters were sacrificed at PND 7 immediately following the maternal aggression test with between 10 and 14 females per group per receptor type being used. A summary of the research design can be found in Table 1 .

\section{RATING OF NEST QUALITY}

Late-gestation females were checked for new litters twice per day. As soon as a new litter was identified the nest quality was scored on a 0-5 scale as follows: 5 - all pups are licked clean (no signs of placental tissue on body of pup) and are located inside a well-built nest; $4-\mathrm{a}$ well-built nest is present but one pup is found to be either not fully licked clean or located outside of the nest; 3 - two or more pups are not retrieved into the well built nest site and/or are unclean; 2 -some pups have been retrieved to the nest location but only a rudimentary nest has been built; 1 - the majority of pups are scattered throughout the cage with only a rudimentary nest built; 0 - all pups are scattered throughout cage and no nest site is identifiable.

\section{PUP RETRIEVAL TEST}

On the day of birth, the lactating female and pups were removed from the home cage briefly (approximately $10 \mathrm{~s}$ ) and bedding was disturbed throughout the cage. Three pups from the litter were then randomly placed away from the nest end of the home cage, and the mother was then reintroduced to the cage. The latency (in seconds) to sniff a pup, retrieve each of three pups, nestbuild and crouch over pups was recorded. If a female had not completed this response within $15 \mathrm{~min}$ the test was terminated, resulting in a latency of $900 \mathrm{~s}$ for any behaviors not yet observed. Following testing, all pups were returned to the home cage. All testing occurred within the colony room.

\section{MATERNAL OBSERVATIONS}

The procedure for assessing maternal behavior in mice was adapted from previous work examining natural variations in maternal care in rats (Champagne et al., 2003a). Maternal behavior was scored from PND 1 to PND 6. Observers were trained to a high level of inter-rater reliability (i.e., $>0.90$ ). Dams were observed in their home cage during the dark-phase of the light cycle under dim red light ( $<5$ lux) and not disturbed for the duration of the 6-day observation period. Each day consisted of four observation periods, two within the first $5 \mathrm{~h}$ following the onset of the dark cycle (0800 to 1300) and 2 within $7 \mathrm{~h}$ of the end of the dark cycle (1300 to 2000). Each observation was $60 \mathrm{~min}$ in duration and no observation sessions took place within the 1-h period before or after the transition from the light to dark cycle. Within each observation period, the behavior of each mother was scored every 3 min (20 observations/period $\times$ four periods per day $=80$ observations/ mother $/$ day $=480$ observations per mother over the 6 days). The following behaviors were scored: mother off pups, mother licking and grooming any pup (both body and anogenital licking were included), mother in nursing posture over pups, mother in contact with pups but not nursing, nest-building, self-grooming, eating and drinking. Variations in nursing posture previously observed in lactating rat dams were not evident in the 6 days postpartum and nursing thus describes a crouched arch posture over pups. We have used this method in previous studies of natural variations in maternal care in 129Sv, C57BL/6 and Swiss mice (Champagne et al., 2007).

\section{Table 1 | Summary of research design.}

\begin{tabular}{|c|c|c|c|}
\hline Generation & Description & Tests and measures & Time/age of assessm \\
\hline FO & $\begin{array}{l}\text { Lactating dams rearing cross-fostered } \\
\text { offspring in standard vs. communal nests }\end{array}$ & Frequency of postpartum maternal behavior & Postpartum days 1-6 \\
\hline \multirow[t]{6}{*}{$\mathrm{F} 1$} & Male and female offspring reared in standard & Weights (g) & PND 1, 28, 35, 60 \\
\hline & vs. communal nests & Open-field testing & PND 65 (adulthood) \\
\hline & $\begin{array}{l}\text { Female offspring, mated at PND 70, } \\
\text { rearing own offspring in standard nests }\end{array}$ & $\begin{array}{l}\text { Litter size, weight, and performance in a } \\
\text { retrieval test }\end{array}$ & Postpartum day 0 \\
\hline & & Frequency of postpartum maternal behavior & Postpartum days 1-6 \\
\hline & & Lactational aggression & Postpartum day 7 \\
\hline & & $\begin{array}{l}\text { Hypothalamic receptor binding density } \\
\text { (OT and V1a) }\end{array}$ & Postpartum day 28 \\
\hline \multirow[t]{6}{*}{ F2 } & Female grand-offspring that are reared in & Weights (g) & PND 1 \\
\hline & $\begin{array}{l}\text { standard nests by F1 communal vs. standard } \\
\text { reared female offspring }\end{array}$ & Open-field testing & PND 65 (adulthood) \\
\hline & Female offspring, mated at PND 70, rearing & Litter size, weight, and latency to retrieve pups & Postpartum day 0 \\
\hline & own offspring in standard nests & Frequency of postpartum maternal behavior & Postpartum days 1-6 \\
\hline & & Lactational aggression & Postpartum day 7 \\
\hline & & Hypothalamic receptor binding density (OT and $\mathrm{V} 1 \mathrm{a}$ ) & Postpartum day 7 \\
\hline
\end{tabular}




\section{OPEN-FIELD TEST}

The open field test is a standard tool for measuring exploratory and anxiety-like behavior in rodents (for reviews see Archer, 1973; Crawley, 1985; Belzung and Griebel, 2001). The open-field used was a $24^{\prime} \times 24^{\prime} \times 16^{\prime}$ plastic box. The sides of this box were black and the floor consisted of white tiles. The behavior of the animal in this field was recorded with a video camera mounted on a tripod adjacent to the field. Coding of these video recordings was completed using a DOS-based program designed to give summaries of the amount of time spent in the inner and outer area of the field, as well as the overall activity of the animal. Mice were tested in the open-field at approximately 65 days of age and females were confirmed to be in diestrus on the day of testing following analysis of the cytology of a vaginal smear. On the day of testing, the mouse was removed from its home cage and placed directly into one corner of the open field. After a 10-min session, the mouse was removed and returned to its home cage. Counts of fecal boli were assessed at this time. All testing was conducted under red (dark phase) lighting conditions. During analysis of the recordings, the field was divided into a grid of $10 \times 10$ squares. For the purposes of analysis, inner field exploration was defined as the time spent in the inner $9 \times 9$ squares, activity was defined as the number of square crossings and pauses in movement within the field were defined as the duration of time spent immobile. The length of time spent immobile is a measure created from a log starting $5 \mathrm{~s}$ after the rodent stops engaging in grid crossings during the test and indicates the duration of time during which there are no grid crossings. Though there may be some aspects of "freezing" included in this measure, it is a more general indicator of immobility.

\section{MATERNAL AGGRESSION}

On postpartum day 7 , each Balb/c female was exposed to an intruder male for $7 \mathrm{~min}$ in her home-cage. All tests took place between 4 and $7 \mathrm{~h}$ after the onset of the dark light cycle. Immediately prior to the behavioral test, pups were removed from the home-cage. Previous work has demonstrated that removing pups does not diminish the expression of maternal aggression in mice (Svare et al., 1981). Postpartum day 7 was chosen as this is within the period of high levels of maternal aggression in mice that occurs between postpartum days 4 and 10 (Svare, 1990). At the commencement of the test, an adult, group-housed, virgin Balb/c intruder male was placed in the dam's home cage at the opposite end from the nest-site. Each test was recorded on videotape and reviewed post-test to analyze maternal aggression. No male was used more than twice, with F1 and F2 standard and communal females receiving males with equal levels of previous test experience. Males were given at least 1 day of rest between tests. The latency, frequency and total duration of the following behaviors were quantified by individuals blind to the rearing condition of females - sniff the male, bite the male's head/neck or flank (aggressive behaviors); freeze when approached by the male, run away from the male, or establish a subordinate posture - the female stands on her hind legs with her paws upright and nape displayed (subordinate behaviors). In addition, in this study we observed high levels of tail rattling in F2 females so this was recorded. Tests were to be immediately terminated if overt aggression was observed, although this was not the case with any females tested in this study. Females who did not display a given behavior during the 7-min test were assigned a latency of $420 \mathrm{~s}$ for that behavior.

\section{OT AND V1A RECEPTOR AUTORADIOGRAPHY}

Mice were sacrificed through rapid decapitation and brains extracted, placed briefly in isopentane, and stored at $-80^{\circ} \mathrm{C}$. Brains were sectioned in the coronal plane at $20 \mu \mathrm{m}$, and sections thaw mounted onto poly-L-lysine coated slides that were stored at $-80^{\circ} \mathrm{C}$ until the assay was performed. Slide-mounted coronal brain sections were processed for OT receptor autoradiography using $\left.{ }^{125} \mathrm{I}-\mathrm{d}\left(\mathrm{CH}_{2}\right)_{5}[\mathrm{Tyr}-\mathrm{Me})_{2}, \mathrm{Tyr}-\mathrm{NH}_{2}{ }^{9}\right]$ OVT (New England Nuclear, Boston, MA, USA) and V1a receptor autoradiography using ${ }^{125} \mathrm{I}$-lin-vasopressin $\quad\left[{ }^{125} \mathrm{I}\right.$-phenylacetyl-D-Tyr(ME)-PheGln-Asn-Arg-Pro-Arg-Tyr- $\mathrm{NH}_{2}$ ] (New England Nuclear, Boston, MA, USA) as previously described (Francis et al., 2000, 2002). All autoradiograms were analyzed using an image-analysis system (MC1D-4, Interfocus Imaging, Cambridge, UK). Between three and six sections were analyzed bilaterally for each brain region. OT receptor binding was analyzed rostrally between Bregma +0.74 and $+0.26 \mathrm{~mm}$ in the dorsal lateral septum, ventral lateral septum, dorsal endopiriform nucleus and the agranular insular cortex. The same regions were also analyzed caudally between Bregma +0.26 and $+0.02 \mathrm{~mm}$ as was the dorsal bed nucleus of the stria terminalis (BNST). V1a receptor binding analysis was restricted to the dorsal lateral septum and ventral lateral septum both rostrally and caudally (see Figure 6). Sections that did not contain the region of interest and brains that had too few sections were excluded from the analysis. For each animal, total and non-specific binding was measured for each region and the difference taken to yield specific binding which was converted to fmol/mg using microscales (GE Healthcare). The statistical analysis was performed on the mean of these values for each animal by brain region according to the mouse brain atlas (Paxinos and Franklin, 2003). Analysis of mean receptor density values was conducted using $t$-tests with subsequent correction for analyses of multiple regions within each receptor type and level (rostral vs. caudal).

\section{RESULTS \\ EFFECTS OF STANDARD VS. COMMUNAL REARING CONDITIONS ON FO MATERNAL BEHAVIOR}

Prior to cross-fostering of pups, those F0 Balb/c females designated to standard vs. communal rearing conditions were found to display equivalent nest qualities and levels of motivation to sniff, retrieve, nestbuild and crouch over pups during the pup retrieval test conducted on PND 0 (data not shown). However, differences in maternal behavior were apparent during home-cage observations conducted after the implementation of the standard vs. communal rearing conditions. Repeated measures ANOVA with postnatal day as within- and rearing condition as between-group factors indicated a main effect of rearing condition $[\mathrm{F}(1,19)=5.22, p<0.05]$ and a main effect of day $[\mathrm{F}(5,19)=3.12, p<0.05]$ on frequency of nursing-contact with pups. Communally rearing females engaged in higher levels of nursing-contact than standard rearing females and this behavior decreased across days in both groups (Figure 1A). In contrast, non-nursing contact was elevated in standard compared to communally rearing females $[\mathrm{F}(1,19)=11.29, p<0.001$; Figure 1B] Analysis of LG behavior indicated a trend for increased licking 

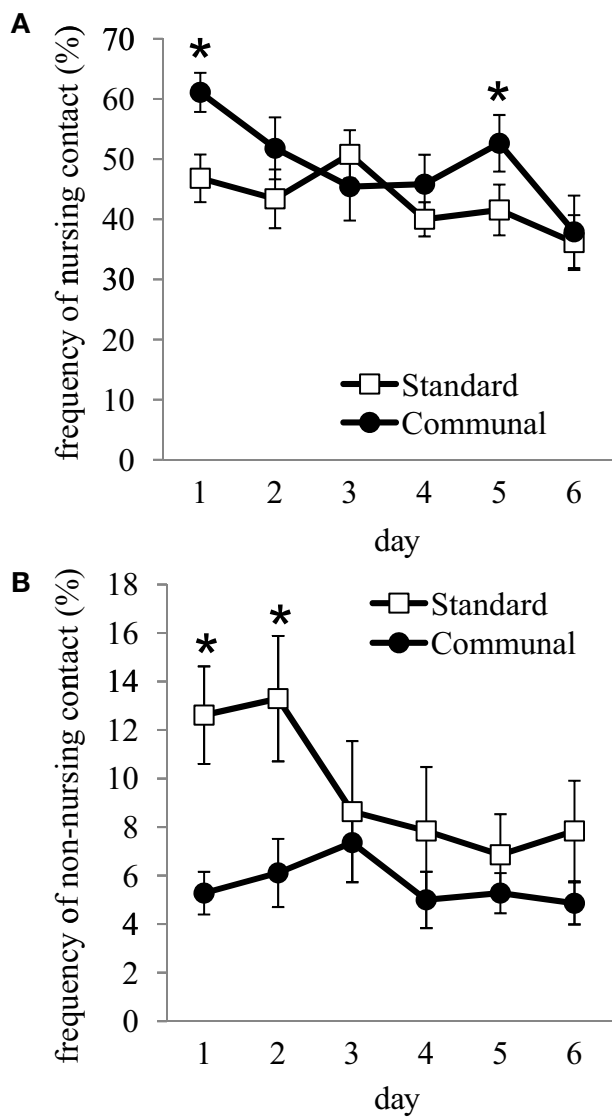

FIGURE 1 | Postpartum maternal behavior amongst females rearing pups in standard vs. communal nests. Frequency of (A) nursing-contact was significantly elevated amongst communal females whereas (B) non-nursing contact was reduced in communal compared to standard rearing females.
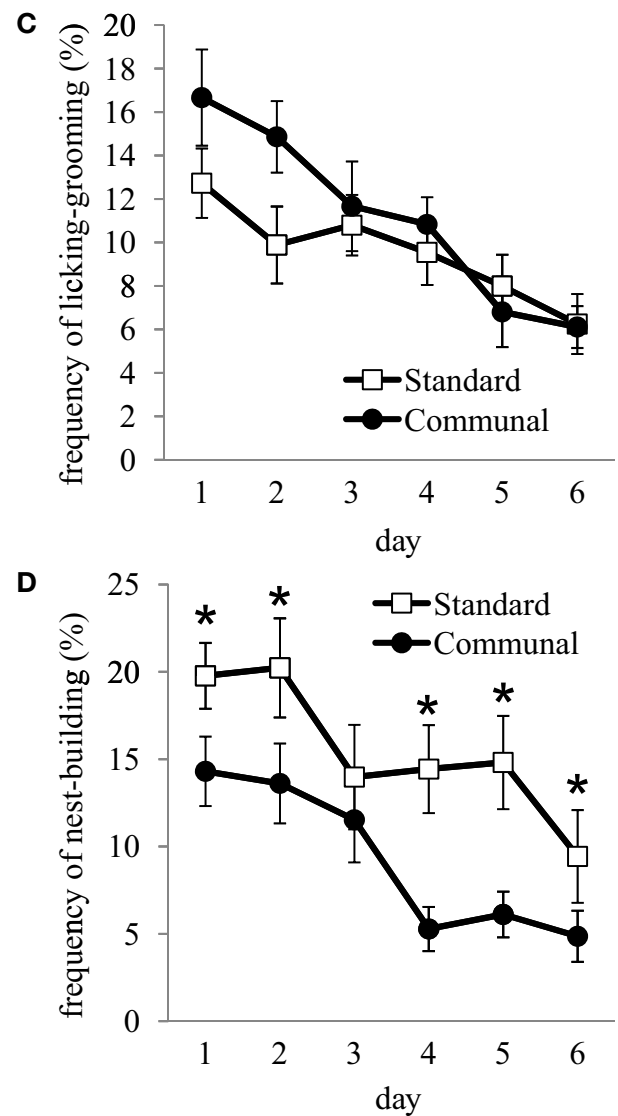

Though overall levels of (C) licking/grooming did not differ as a function of rearing condition, there was a trend for communal to lick pups more frequently, particularly early in the postpartum period. (D) Nest-building was observed more frequently amongst standard compared to communal females. ${ }^{*} p<0.05$. amongst communally nursing females $[\mathrm{F}(1,19)=3.08, p=0.08]$ with both groups decreasing frequency of this behavior across days $[\mathrm{F}(5,19)=7.76, p<0.001$; Figure $1 \mathrm{C}]$. Frequency of nest-building was found to be significantly decreased amongst communally rearing females $[F(1,19)=20.28, p<0.001$; Figure 1D] and self-grooming was elevated in the communal group $[\mathrm{F}(1,19)=9.7, p<0.01]$. No effects of rearing condition were found on the frequency of eating, drinking, or in time spent off the nest.

\section{EFFECTS OF STANDARD VS. COMMUNAL REARING CONDITIONS ON GROWTH OF OFFSPRING}

Analysis of average pup weight at PND 6 indicated no group differences as a function of rearing condition [standard $=3.46 \pm 0.15 \mathrm{~g}$; communal $=3.53 \pm 0.13 \mathrm{~g}$ ]. However, repeated measures ANOVA of individual offspring weights at weaning (PND 28), PND 35, and day 60 indicated a significant sex by rearing condition by time interaction $[\mathrm{F}(2,99)=5.14, p<0.01]$. Post hoc analysis indicated that at PND 28 there were no sex differences in weight of communally reared offspring whereas sex differences were apparent amongst standard reared males and females $[p<0.001$; standard: males $=14.41 \pm 0.37 \mathrm{~g}$, females $=12.22 \pm 0.48 \mathrm{~g}$; communal: males $=13.45 \pm 0.36 \mathrm{~g}$, females $=13.20 \pm 0.31 \mathrm{~g}]$. However, this rearing condition by sex interaction was not significant at PND 35 or day 60 and sex differences in weight were significant in both groups at these time-points.

\section{EFFECTS OF STANDARD VS. COMMUNAL REARING CONDITIONS ON F1 OFFSPRING OPEN-FIELD EXPLORATION}

Two-way ANOVA indicated a main effect of rearing condition on the number of fecal boli produced during testing $[\mathrm{F}(1,99)=4.67$, $p<0.05$ ] indicating that both male and female offspring who had been communally reared produced fewer boli. Time spent immobile during testing was also found to be lower amongst communally reared offspring $[\mathrm{F}(1,99)=5.38, p<0.05]$ though overall activity (number of grid-crossings during testing) and time spent in the inner area of the apparatus did not differ as a function of rearing condition (Table 2).

\section{EFFECTS OF STANDARD VS. COMMUNAL REARING CONDITIONS ON F1 OFFSPRING MATERNAL BEHAVIOR}

Analysis of litter size and litter weight of pups born to F1 offspring indicated no effect of rearing condition (data not shown). F1 females who had been communally reared were found to have a higher nest quality than standard reared females [standard $=3.4 \pm 0.29$, commu$\mathrm{nal}=4.2 \pm 0.21 ; \mathrm{t}(30)=2.11, p<0.05]$. Analysis of latency (in seconds) 
Table 2 | Open-field behavior of F1 standard vs. communal reared offspring.

\begin{tabular}{lllccc}
\hline Rearing condition & Sex & Number of boli & Time spent immobile & Time spent in the inner area & Total squares crossed \\
\hline Standard & Male & $8.79 \pm 0.64$ & $69.96 \pm 15.20$ & $130.22 \pm 19.97$ & $689.90 \pm 68.46$ \\
& Female & $8.48 \pm 0.80$ & $106.19 \pm 22.13$ & $104.54 \pm 22.40$ & $596.60 \pm 107.48$ \\
Communal & Male & $7.08 \pm 0.71^{*}$ & $49.16 \pm 7.74^{*}$ & $103.86 \pm 18.18$ & $563.88 \pm 50.05$ \\
& Female & $7.24 \pm 0.55^{*}$ & $57.12 \pm 10.76^{*}$ & $81.57 \pm 15.33$ & $552.96 \pm 57.61$
\end{tabular}

* Significant difference in communal compared to standard reared, $p<0.05$.

to approach and retrieve three pups indicated that communally reared females had decreased latencies to retrieve all three pups compared to standard reared females $[\mathrm{t}(30)=2.55, p<0.05$; Figure 2]. No rearing effects were found on the latency to sniff, nest-build or crouch over pups during testing. Differences in retrieval latencies were found to be primarily due to rearing effects on the number of females that were observed to engage in retrieval compared to those that were not observed to retrieve pups during the 15-min test. Amongst standard reared females, $43.5 \%$ were observed to retrieve pups whereas $87.5 \%$ of communally reared females retrieved pups, an effect found to be significant using chi-square analysis $\left[\chi^{2}(1)=4.99, p<0.05\right]$.

Repeated measures analysis of postpartum maternal behavior indicated that communally reared F1 offspring exhibited significantly higher frequencies of nursing-contact $[\mathrm{F}(1,30)=5.3$, $p<0.05$; Figure $3 \mathrm{~A}]$, non-nursing contact $[\mathrm{F}(1,30)=3.85, p<0.05$; Figure 3B $]$, and pup LG $[\mathrm{F}(1,30)=6.30, p<0.05$; Figure $3 \mathrm{C}]$. Conversely, standard reared females were more frequently off the nest and not in contact with pups compared to communally reared females $[F(1,30)=8.48, p<0.01]$. No effects of rearing condition were observed on the frequency of nest-building (Figure 3D), selfgrooming, eating or drinking.

Aggression toward an intruder male was compared amongst lactating standard vs. communally reared females (Table 3). Latency to engage in a submissive defensive freezing posture was significantly decreased in communally compared to standard reared females and communal females were found to spend more time in this posture throughout testing. In contrast, latency to bite the intruder male was increased in communally reared females and communal females were less frequently observed to bite males during testing.

\section{EFFECTS OF STANDARD VS. COMMUNAL REARING CONDITIONS ON F2 OFFSPRING OPEN-FIELD EXPLORATION}

Adult female offspring of F1 standard vs. communally reared females were tested as in the F1 generation on measures of openfield exploration. F2 offspring of communally reared females were found to spend less time immobile $[\mathrm{t}(22)=2.38, p<0.05]$ and display higher levels of activity $[\mathrm{t}(30)=2.38, p<0.05]$ compared to F2 offspring of standard reared females (Table 4). F2 communally reared females were also found to spend more time in the inner area of the open-field $[\mathrm{t}(22)=2.90, p<0.01]$. No group differences were found in the number of fecal boli produced during testing.

\section{EFFECTS OF STANDARD VS. COMMUNAL REARING CONDITIONS ON F2 OFFSPRING MATERNAL BEHAVIOR}

F2 communal females were found to have larger litter sizes $[\mathrm{t}(29)=$ $2.28, p<0.05 ;$ standard $=7.00 \pm 0.50$, communal $=8.57 \pm 0.45]$ and

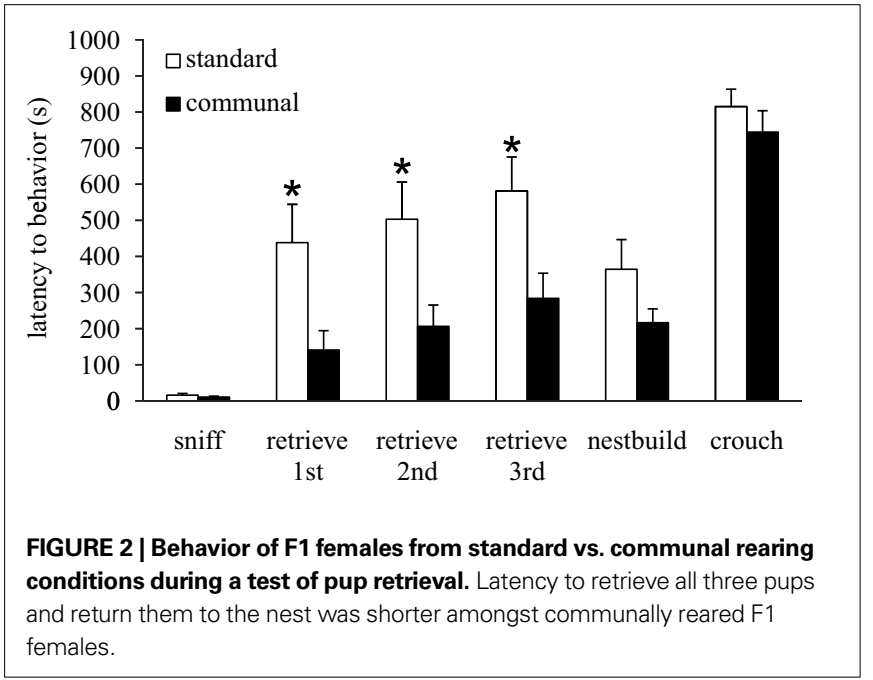

litter weights $[\mathrm{t}(29)=2.79, p<0.01$; standard $=10.27 \pm 0.56 \mathrm{~g}$, com munal $=12.34 \pm 0.45 \mathrm{~g}]$ compared to F2 standard females though average pup weight did not significantly differ. No significant differences were found on measures of nest quality on PND 0 (standard $=4.24 \pm 0.20$; communal $=4.29 \pm 0.27$ ) or in latency to sniff or retrieve pups (Figure 4). There was a trend for F2 communal females to engage in retrieval behavior during testing more frequently than F2 standard females [standard $=64.7 \%$; communal $=78.6 \%$, $p=0.08]$.

Overall, frequency of nursing behavior during the postpartum period was not found to differ between standard and communal F2 females, though there was a significant elevation in nursing-contact by F2 communal females on PND $1 \quad(p<0.05$ Figure 5A). Non-nursing contact was found to be decreased in F2 communal females from PND 1-6 $[\mathrm{F}(1,30)=5.39, p<0.05$; Figure 5B]. No group differences were found in the frequency of LG (Figure 5C), nest-building (Figure 5D), self-grooming, eating, drinking, and time spent off the nest. Analysis of behavior during exposure to an intruder male indicated no group differences in aggressive or subordinate behaviors (data not shown), though F2 standard females were observed to spend more time tail rattling during testing $[\mathrm{t}(27)=2.16, p<0.05$; standard $=9.75 \pm 3.54 \mathrm{~s}$, communal $=1.19 \pm 0.66 \mathrm{~s}]$.

\section{V1A AND OT RECEPTOR BINDING IN F1 AND F2 STANDARD AND COMMUNAL FEMALES}

In F1 dams at day $28 \mathrm{PND}$, communally reared dams had significantly elevated caudal oxytocin receptor binding compared to 
A

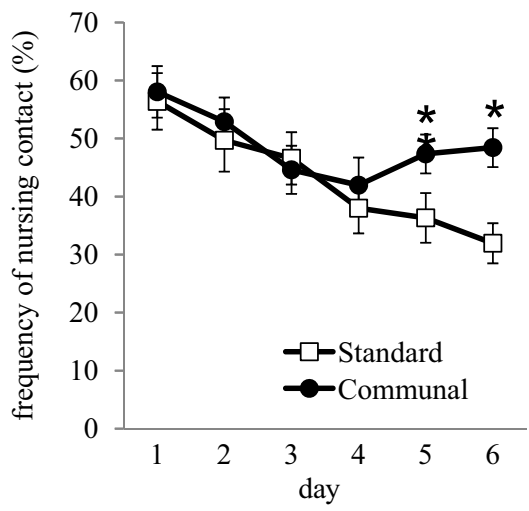

B

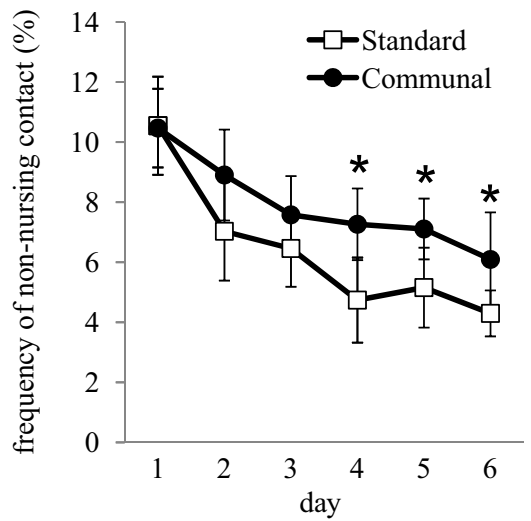

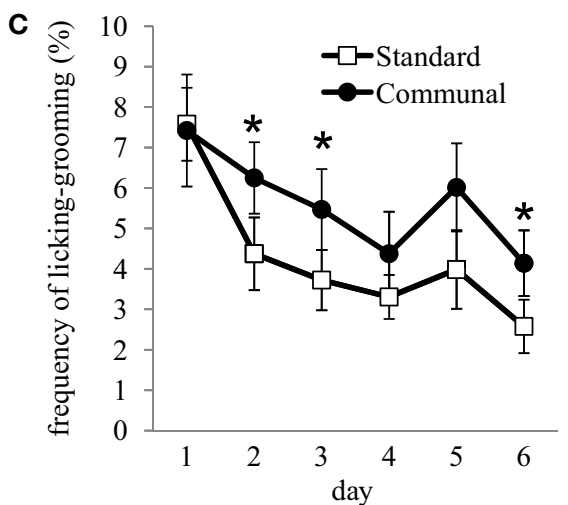

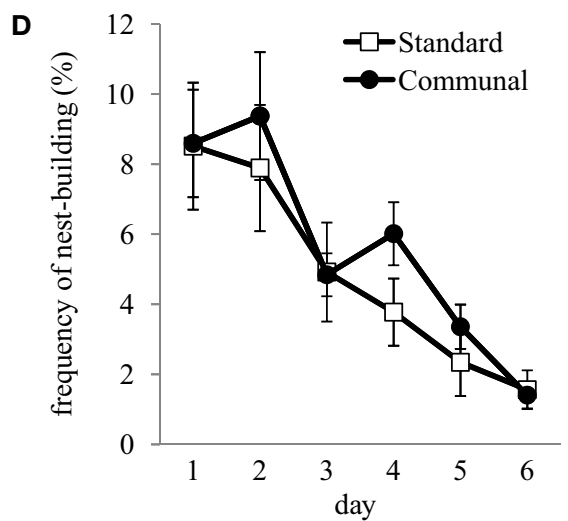

FIGURE 3 | Postpartum maternal behavior amongst F1 standard and communally reared females. Frequency of (A) nursing-contact, (B) non-nursing contact, and (C) licking/grooming was significantly elevated amongst communal females. (D) Nest-building did not differ amongst standard compared to communally reared females. ${ }^{*} p<0.05$

Table 3 | Lactational aggression of F1 standard vs. communally reared offspring.

\begin{tabular}{lcc}
\hline Behavior & Standard & Communal \\
\hline LATENCY (S) & & \\
Sniff & $6.7 \pm 1.0$ & $8.6 \pm 1.5$ \\
Run away & $243.4 \pm 41.0$ & $253.7 \pm 45.4$ \\
Subordinate posture & $226.2 \pm 35.8$ & $234.1 \pm 35.1$ \\
Defensive freeze & $\mathbf{2 4 4 . 0} \pm \mathbf{3 2 . 3}$ & $\mathbf{1 6 0 . 1} \pm \mathbf{2 4 . 3}$ \\
Bite & $\mathbf{1 0 3 . 2} \pm \mathbf{3 6 . 6}$ & $\mathbf{2 2 2 . 2} \pm \mathbf{4 4 . 4 ^ { * }}$ \\
FREQUENCY & & \\
Sniff & $13.0 \pm 1.3$ & $10.8 \pm 0.8$ \\
Run away & $1.1 \pm 0.3$ & $1.4 \pm 0.5$ \\
Subordinate posture & $3.8 \pm 1.0$ & $5.4 \pm 1.2$ \\
Defensive freeze & $3.3 \pm 0.8$ & $4.7 \pm 0.5$ \\
Bite & $\mathbf{3 . 9} \pm \mathbf{0 . 7}$ & $\mathbf{1 . 9} \pm \mathbf{0 . 6}$ \\
TOTAL DURATION (S) & & \\
Sniff & $32.9 \pm 4.4$ & $31.2 \pm 3.0$ \\
Run away & $1.2 \pm 0.3$ & $1.7 \pm 0.7$ \\
Subordinate posture & $36.1 \pm 16.8$ & $27.4 \pm 6.7$ \\
Defensive freeze & $\mathbf{1 2 . 7} \pm \mathbf{3 . 6}$ & $\mathbf{2 3 . 2} \pm \mathbf{3 . 7}$ \\
Bite & $7.9 \pm 1.7$ & $4.0 \pm 1.7$ \\
& &
\end{tabular}

${ }^{*} p<0.05$, Bold represents significant differences. standard reared dams in the dorsal lateral septum $[\mathrm{t}(13)=5.48$, $p<0.001]$, ventral lateral septum [ $\mathrm{t}(13)=11.25, p<0.001]$, dorsal BNST $[\mathrm{t}(13)=11.24, p<0.001]$, posterior part of the agranular insular cortex $[\mathrm{t}(13)=3.20, p<0.01]$ and the dorsal endopiriform nucleus $[\mathrm{t}(13)=3.45, p<0.01$; Table 5$]$. More rostrally, the only significant difference in oxytocin receptor binding was found in the dorsal lateral septum, where communally reared dams had elevated binding compared to standard reared dams $[\mathrm{t}(12)=2.83, p<0.05]$. With regard to vasopressin $\mathrm{V} 1$ a receptors, $\mathrm{F} 1$ standard reared dams had elevated V1a receptor binding in the caudal part of the dorsal lateral septum compared to dams who had been reared in the communal condition $[\mathrm{t}(12)=2.21, p<0.05]$. No significant differences were found in the rostral part of the dorsal lateral septum or in the ventral lateral septum. Amongst F2 females at day 7 PND, dams in the standard reared lineage had higher V1ar binding in the rostral dorsal lateral septum $[\mathrm{t}(26)=3.94, p<0.01]$, and a trend towards lower oxytocin receptor binding in the rostral ventral lateral septum $[\mathrm{t}(23)=2.02, p=0.055]$ than those dams in the communally reared lineage. No other significant differences were observed between F2 dams in the standard or communal lineages.

\section{DISCUSSION}

In the current study we provide evidence for the impact of communal rearing on Balb/c mice and demonstrate the ameliorating effects that this variation in the early social environment can have on a 
Table 4 | Open-field behavior of F2 standard vs. communal female offspring.

\begin{tabular}{llccc}
\hline Rearing condition & Number of boli & Time spent immobile (s) & Time spent in the inner area (s) & Total squares crossed \\
\hline Standard & $9.16 \pm 0.80$ & $139.30 \pm 35.56$ & $55.70 \pm 19.13$ & $472.00 \pm 103.98$ \\
Communal & $9.25 \pm 1.18$ & $40.03 \pm 21.86^{*}$ & $135.94 \pm 19.92^{* *}$ & $773.83 \pm 72.36^{*}$ \\
\hline
\end{tabular}

Communal vs. standard, ${ }^{*} p<0.05,{ }^{* *} p<0.01$.

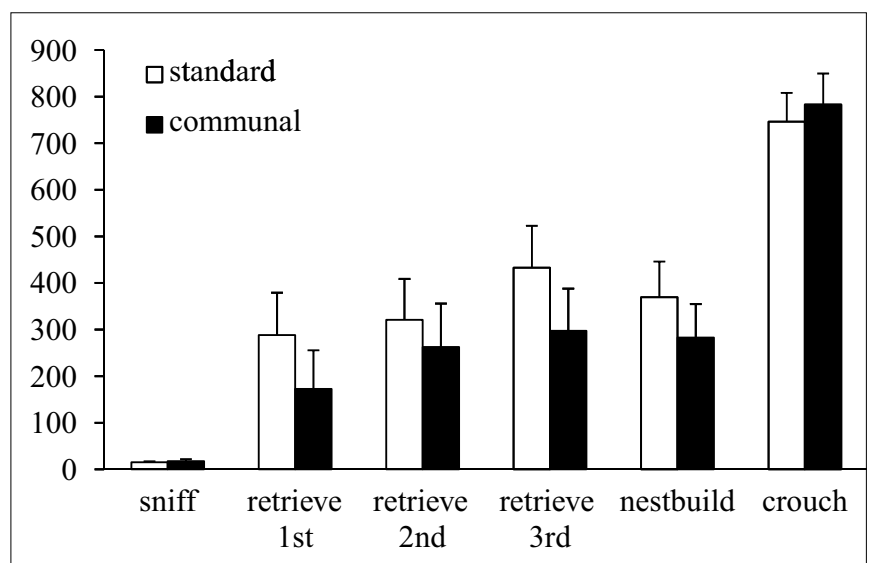

FIGURE 4 | Behavior of F2 females from standard vs. communal rearing conditions during a test of pup retrieval. No significant differences were observed between groups in any behavior.

stress-sensitive and socially impaired mouse strain. Importantly, these early rearing effects persist in the absence of continued social enrichment and can be observed amongst $\mathrm{F} 2$ female offspring who have never experienced the communal rearing conditions. Though the mechanism of this transmission across generations of early rearing effects has yet to be fully elucidated, our data suggest the possibility that variations in maternal care that are induced in F0 females when rearing offspring in a communal nest combined with the increased peer interactions amongst the large communal litters may alter neural systems which regulate exploratory, social and reproductive behavior in offspring. Consequently, when F1 offspring are adults, they display reduced anxiety-like behavior and females display increased maternal motivation and care which alters the development of F2 offspring.

Though Balb/c female mice have previously been demonstrated to exhibit low levels of particular forms of maternal care, including LG and nursing behavior (Roy et al., 2007), here we demonstrate that when the rearing dynamics of the postpartum environment are altered, there are significant increases in nursing-contact and a trend toward increased LG in Balb/c dams. These data are consistent with previous observations of communally nursing female mice (Branchi et al., 2006a) and highlight the contextual determinants of maternal care. Though individual differences in maternal care can be predicted by the quality of the postnatal (Lovic et al., 2001) and juvenile environment (Champagne and Meaney, 2007), the quality of the perinatal environment of adult females may also be capable of shifting patterns of maternal behavior. This has been most clearly shown in response to gestational stress, which typically leads to decreased levels of pup LG (Champagne and Meaney, 2006) and reduced frequency of nursing in rodent studies (Smith et al.,
2004). In primates and rodents, variable foraging demand during the postnatal period leads to alterations in the dynamics of the mother-infant interaction (Rosenblum and Paully, 1984; Coutellier et al., 2009), with consequences for offspring development. The increased level of social interaction within the communal nest may provide an enriched environment for post-parturient females which may facilitate pup directed behavior. The increased physical interaction associated with social contact has been demonstrated to increase oxytocin release leading to reduced anxiety (UvnasMoberg, 1997). These combined effects may lead to increased social behavior, and amongst communally nesting females, lead to increased mother-infant interactions.

The communal nursing paradigm was initially developed in the laboratory to examine reproductive success and to elucidate those factors that lead to cooperative vs. antagonistic interactions between post-parturient females (Sayler and Salmon, 1969, 1971; Manning et al., 1992; Konig, 1994). Consistent with this previous literature, we found high levels of maternal investment in the communal litter even amongst unrelated Balb/c females caring for foster pups and there were no differences in mortality between standard and communal reared litters. Literature regarding the effects of communal rearing on growth rates has been somewhat inconsistent, the most reliable and robust increases in growth usually present when the ratio of mothers to pups is increased (Sayler and Salmon, 1969). In the present study, the ratio of mothers to pups was similar between standard and communally reared nests and as predicted we did not find significant elevations in weaning weights amongst communal litters. However, we did observe a transient rearing effect on sexual dimorphism in weaning weight, with communally reared males and females exhibiting no significant differences in weight at PND 28. These data suggest that males and females may respond differentially to this early rearing paradigm or there may be differences in maternal interactions as a function of the sex of the pup that are present in standard vs. communal litters. As we did not distinguish between male and female pups when conducting observations of the litters, we are unable to determine if maternal investment is varying as a function of sex of the pup. Previous studies of prenatal stress, neonatal handling and maternal separation have provided evidence for sex differences in sensitivity to early rearing effects, with males typically found to be more sensitive to the long-term effects of these experiences (Park et al., 2003; Slotten et al., 2006; Mueller and Bale, 2007, 2008). However, based on the analysis of open-field behavior of male and females reared in standard vs. communal nests, it would appear that both sexes are equally affected by this rearing paradigm.

Enrichment of the quality and quantity of social interaction during the postnatal and postweaning period has previously been demonstrated to decrease behavioral and physiological indices 

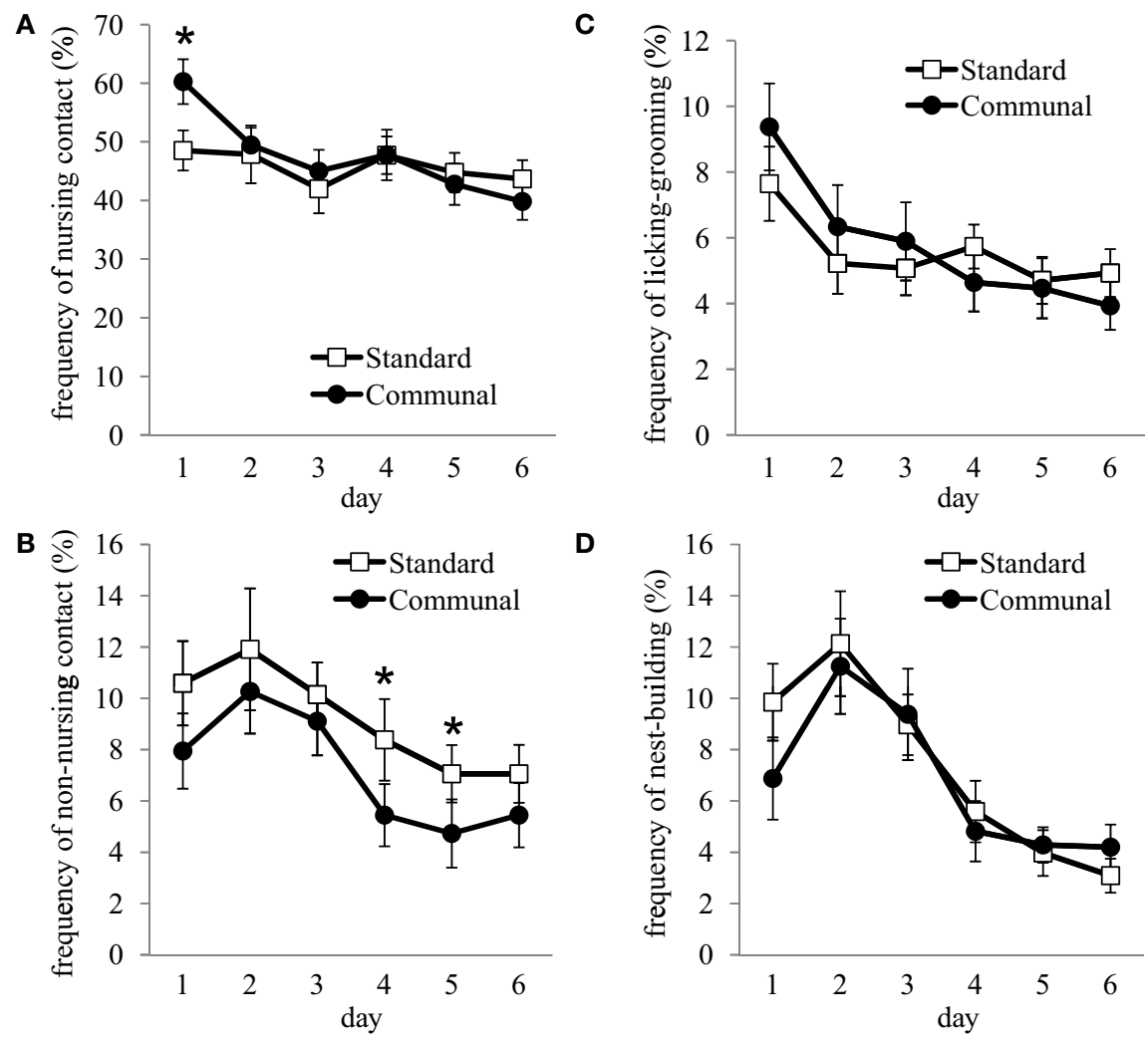

FIGURE 5 | Postpartum maternal behavior amongst $F 2$ standard and communal females. Though frequency of (A) nursing-contact did not significantly vary between groups overall, there were significant elevations in this behavior

amongst communal females on PND 1. (B) Non-nursing contact was reduced in communal compared to standard females. No significant differences were observed in the frequencies of (C) licking/grooming or (D) nest-building. ${ }^{*} p<0.05$

Table 5 | Oxytocin and vasopressin V1a receptor binding in F1 and F2 females.

F1 dams (28 PND)

\section{Standard}

\section{OXYTOCIN RECEPTOR ROSTRAL (FMOL/MG)}

Dorsal lateral septum

Ventral lateral septum

Dorsal endopiriform nucleus

Agranular insular cortex, ventral part

\section{OXYTOCIN RECEPTOR CAUDAL (FMOL/MG)}

Dorsal lateral septum

Ventral lateral septum

Dorsal endopiriform nucleus

Agranular insular cortex, posterior part

Dorsal bed nucleus of the stria terminalis

\section{VASOPRESSIN V1A RECEPTOR ROSTRAL (FMOL/MG)}

Dorsal lateral septum

$42.56 \pm 3.47$

Ventral lateral septum

$37.50 \pm 2.30$ $\mathbf{2 1 . 7 6} \pm \mathbf{1 . 0 2}$

$29.93 \pm 1.72$

$51.02 \pm 2.75$

$45.90 \pm 3.14$

\section{VASOPRESSIN VIA RECEPTOR ROSTRAL (FMOL/MG)}

F2 dams (7 PND)

\section{Communal}

Standard

Communal

$28.50 \pm 2.68 *$

$\mathbf{2 8 . 5 0} \pm \mathbf{2 . 6 8 *}$

$30.91 \pm 0.20$

$51.17 \pm 2.16$

$48.17 \pm 2.77$
$23.79 \pm 1.81$

$27.64 \pm 1.35$

$41.78 \pm 1.61$

$40.60 \pm 1.79$
$26.97 \pm 3.36$

$33.86 \pm 2.85^{t}$

$42.58 \pm 1.47$

$40.69 \pm 2.16$
VASOPRESSIN V1A RECEPTOR CAUDAL (FMOL/MG)
Dorsal lateral septum
Ventral lateral septum $\mathbf{4 7 . 2 7} \pm \mathbf{1 . 6 2}$

$43.08 \pm 1.58$
$51.46 \pm 2.32 * * *$

$58.86 \pm 1.83 * *$

$53.33 \pm 2.07 * *$

$28.26 \pm 1.15 * * *$
$40.56 \pm 2.17 * * *$
$36.59 \pm 2.32$

$44.93 \pm 2.29$

$46.27 \pm 1.39$

$43.09 \pm 1.15$

$23.13 \pm 1.01$
$33.45 \pm 2.40$

$42.35 \pm 3.56$

$43.36 \pm 1.84$

$41.28 \pm 1.34$

$22.46 \pm 1.68$
${ }^{*} p<0.05,{ }^{*} p<0.01,{ }^{* * *} p<0.001,{ }^{+} p=0.055$, Bold represents significant differences.

$\begin{array}{lll}44.92 \pm 1.88 & \mathbf{5 4 . 1 3} \pm \mathbf{1 . 4 8} & \mathbf{4 1 . 1 9} \pm \mathbf{3 . 7 3 *} \\ 37.82 \pm 3.52 & 45.12 \pm 1.00 & 40.81 \pm 4.41\end{array}$



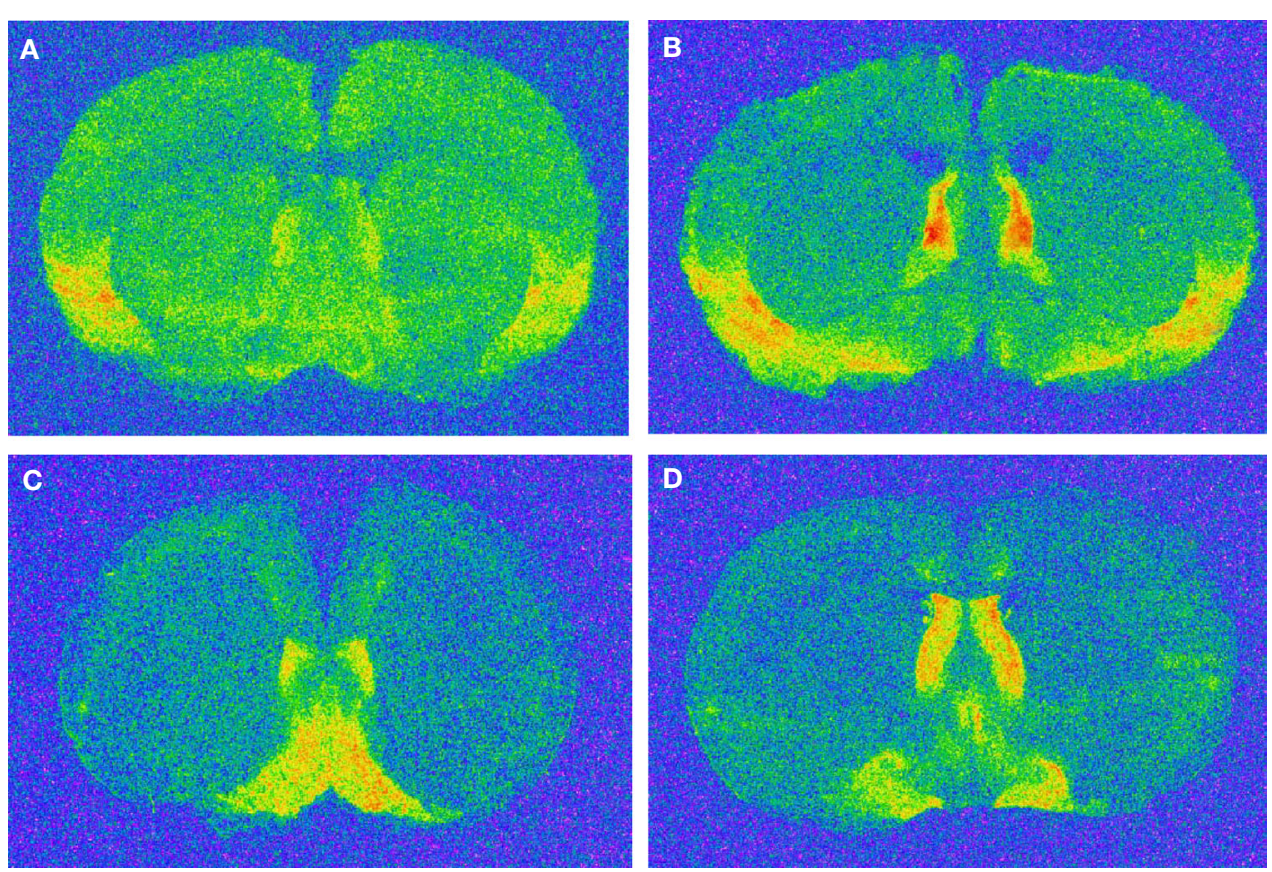

FIGURE 6 | Representative images of regions with oxytocin and vasopressin V1a receptor binding. (A) rostral oxytocin receptor; (B) caudal oxytocin receptor; (C) rostral vasopressin V1a receptor; (D) caudal vasopressin V1a receptor. Please refer to materials and methods for co-ordinates and regions.

of stress responsivity (van Praag et al., 2000; Meaney, 2001) and in many cases ameliorate the heightened hypothamalic-pituitary-adrenal (HPA) activity associated with genetic or early environmental perturbations (Wakshlak and Weinstock, 1990; Arai et al., 2009). In response to communal rearing, we find significant decreases in anxiety-like behavior amongst Balb/c mice, with both males and females producing fewer fecal boli and spending less time immobile during testing. This early environmental "intervention" may be particularly effective when using the Balb/c strain, as previous studies have demonstrated that these mice display elevated stress responses and behavioral inhibition, decreased social motivation, and impaired cognitive ability (Brodkin, 2007). Moreover, embryo transfer and cross-fostering studies have demonstrated that the prenatal and postnatal environment provided by $\mathrm{Balb} / \mathrm{c}$ dams is capable of shifting the phenotype of a less stress-responsive mouse strain $(\mathrm{C} 57 \mathrm{BL} / 6)$ to become more anxious (Francis et al., 2003; Priebe et al., 2005). Stimulating the postnatal environment of rodents using neonatal handling has similarly been shown to decrease HPA activity and compensate for behavioral deficits associated with exposure to prenatal stress or alcohol (Wakshlak and Weinstock, 1990; Weinberg et al., 1995). Based on observations of the natural ecology of mouse rearing dynamics, we would propose that standard laboratory rearing conditions of single dams rearing pups represents a form of early social deprivation whereas communal nesting restores the species typical early environment with consequences for offspring development. In contrast to our findings, previous studies using a variant of the communal paradigm with ICR mice in which pups of different ages are reared by multiple females who have been housed together several days prior to parturition have suggested that communal rearing may increase anxiety-like behavior
(Branchi and Alleva, 2006; Branchi et al., 2006b). Interestingly, the direction of the effect of communal rearing on emotional behavior was dependent on the social context of the behavioral assessment, with reduced anxiety-like behavior emerging when communally reared males were tested in pairs (Branchi and Alleva, 2006). Taken together with our findings, these results suggest the importance of considering strain-specific effects and the specific nature of the early social enrichment in interpreting the long-term developmental consequences.

There is converging evidence from numerous experimental paradigms and longitudinal studies in humans for the impact of variations in postnatal maternal care on the maternal behavior of female offspring. In humans and primates, individual differences in attachment (Benoit and Parker, 1994), mother-infant contact (Fairbanks, 1989) and maternal rejection or abuse (Berman, 1990; Chapman and Scott, 2001; Maestripieri, 2005) have been found to be transmitted from mother to daughter. Amongst laboratory rodents, lactating dams display considerable variability in postnatal LG and nursing which are associated with neuroendocrine effects in female offspring, particularly on hypothalamic receptor expression (Champagne and Meaney, 2001; Champagne et al., 2001). Consequently, as adults, female offspring who had received high levels of maternal care in infancy are more sensitive to the elevated circulating hormone levels that occur in late pregnancy and are thus more "primed" for maternal care (Champagne et al., $2001,2003 b)$. These experiential influences on maternal motivation and behavior are also observed in our analysis of female offspring reared in communal nests. Communally reared F1 females build higher quality nests, retrieve pups more rapidly when the nest is scattered and engage in higher levels of LG and nursing-contact with pups during the postnatal period. Importantly, these effects 
are observed when both communal and standard reared F1 females are rearing their own offspring under standard rearing conditions. The long-term neurobiological changes in F1 offspring that lead to these variations in adult maternal behavior may be driven by the elevated level of care provided to offspring in communal nests and/or by the high level of social contact received through peerpeer interactions in this rearing environment. These maternal and peer/sibling influences may be a critical source of tactile stimulation for developing offspring which serves to increase growth factors and oxytocin release leading to a cascade of neural changes that persist beyond the postnatal period (Pauk et al., 1986; McCarthy et al., 1997).

Analysis of behavior of lactating F1 offspring indicated that communally reared females displayed less aggressive behavior and more submissive behavior towards a male intruder compared to standard reared females. Indeed, communally reared females were more likely to engage initially in freezing behaviors whereas standard reared females were more likely to exhibit aggressive behaviors initially. Few studies have assessed the long-term effects of early social experiences on the future expression of lactational aggression in offspring, however, there is evidence supporting the hypothesis that increased early social contact is associated with reduced levels of future maternal aggression. For instance, female rats who are reared in absence of their mother and siblings are more aggressive and less subordinate when they become dams compared to non-separated females; though this effect can be ameliorated if the maternally isolated females are reared with other pups (Melo et al., 2009). Furthermore, female C57BL/6 mice who were maternally separated during their early life have been found to have shorter latencies to attack intruder males during their own early postpartum period (Veenema et al., 2007). Thus the increased levels of nursing experienced by communally reared offspring and the increased levels of social stimulation received from peers in the communal nest may induce the development of reduced maternal aggression. Similar effects are achieved by altering the level of paternal care amongst biparental mice (Peromyscus californicus), with increased care leading to longer attack latencies in male and female offspring during a resident intruder test (Frazier et al., 2006). Mechanistically, these effects may be mediated directly through altered activity of vasopressin and oxytocin acting directly on maternal circuits (Veenema et al., 2007; Bosch and Neumann, 2008; Nephew and Bridges, 2008a,b; Veenema and Neumann, 2008) or alternatively, they may be mediated via changes to the neural circuits underlying anxiety-like behavior. It has previously been reported that virgin female rats that showed elevated levels of anxiety-like behavior later demonstrated higher levels of maternal aggression (Bosch et al., 2005) though there appears to be some inconsistency across species and strains regarding the relationship between anxiety-like behavior and maternal aggression (Maestripieri and D'Amato, 1991; Lonstein, 2005).

It has been proposed that maternal aggression is an adaptive behavior to enable lactating dams to protect their offspring from potentially infanticidal conspecifics (Agrell et al., 1998). However, dependent upon socio-ecological conditions, the display of such aggression may cause harm to the female and cost her future reproductive opportunities. In environments where communal nursing is the norm and where there are likely to be several males and females sharing a deme with the responsibility to protect offspring, it may be adaptive for the expression of maternal aggression to be reduced. Furthermore, these differences in behavioral strategies employed by communally reared compared to standard reared females may be additional evidence in support of the previously described increased social competence amongst communally reared mice (Branchi et al., 2006a). In a social interaction test, communally reared ICR males are able to establish a social hierarchy more rapidly compared to singly reared offspring (D'Andrea et al., 2007). In our study, communally reared females demonstrated enhanced social competence by being able to rapidly evaluate the larger intruder male and exhibit defensive behaviors more quickly than singly reared females. Though we did not observe a direct inheritance of biting and subordinate phenotypes to the $\mathrm{F} 2$ generation, we did observe higher levels of aggressive tail rattling by F2 standard reared females compared to F2 females whose F1 mothers had been reared communally. Therefore, there appears to be a transmission of maternal aggression across generations which may get weaker when the socio-ecological conditions change (e.g., from communal rearing to single rearing).

Though the study of inherited traits has long been the domain of genetics research, there is increasing evidence for the non-genomic transmission of the effects of environmental experiences across generations. In the present study we demonstrate that the impact of communal rearing can be observed on F1 offspring who had been exposed in infancy to the communal nest and on F2 offspring who had not directly experienced the communal nest but who had been reared by an F1 female. F2 communal female offspring were found to exhibit decreased anxiety-like behavior, spending less time immobile and more time exploring the inner area of the open-field. Though rearing effects on time spent in the inner area were not seen in the previous generation of females, possibly due to the overall heightened levels of inner area exploration exhibited by the fostered F1 offspring in both groups, this behavior in F2 females indicates a similar overall phenotype to F1 females. Moreover, F2 females displayed variations in reproduction and maternal care, with F2 females having larger litters with elevated pup weights and engaging in an increased frequency of nursing on day PND 1 and decreased non-nursing contact from days 1-6 PN; a pattern of postnatal behavior similar to their communally nursing F0 grand-mothers. These findings provide significant evidence for the transgenerational impact of the early rearing experiences in mice and indicate that potentially adaptive changes in response to environmental cues can persist within and across generations. The adaptive value of these rearing effects, though hypothetical within a laboratory setting, can certainly be appreciated. Increased maternal and peer interaction experienced in infancy would likely indicate an enriched social environment in which reduced emotional and increased maternal investment would enhance an individual's capacity for cohabitation within a large social group. The transmission of these effects to the F2 generation would likely better prepare these offspring to function within a socially complex environment.

Research on the transgenerational impact of environmental experiences is rapidly evolving. Previous studies indicate that prenatal protein restriction (Zambrano et al., 2005), in utero exposure to endocrine disruptors (Anway et al., 2005; Newbold 
et al., 2006) and maternal smoking during pregnancy (Li et al., 2005) can induce molecular changes that impact health and development of offspring and grand-offspring. These studies suggest an alteration in epigenetic programming within the germline that alters the development of subsequent generations. Alternatively, transgenerational effects may be mediated through modification of the epigenetic status of genes that regulate reproductive behavior (Champagne, 2008). Epigenetic effects on the expression of hypothalamic estrogen receptor (ER) $\alpha$ has been previously demonstrated to mediate the transmission of variations in maternal LG from mother to daughter with implications for the maternal behavior of grand-daughters (Champagne et al., 2006). Additional evidence of this non-genomic transmission comes from rodent studies of the effects of postnatal abuse and suggests that environmentally induced modification to methylation of the exon IV region of the BDNF gene can be inherited by offspring and grandoffspring through variations in the perinatal mother-infant interaction (Roth et al., 2009). Epigenetic modifications, particularly in the form of DNA methylation, provide a unifying mechanism through which both germline and non-germline inheritance of environmental experiences may be mediated. Though we have yet to explore the role of these mechanisms in mediating the effects of communal rearing on F1 and F2 offspring, previous studies support the likelihood that DNA methylation is a biological pathway linking environmental exposures to long-term neurobiological and behavioral change.

There are numerous neural mechanisms through which social modulation of physiology and behavior can be achieved. In the present study, we have explored the impact of communal rearing on region-specific oxytocin and vasopressin V1a receptor densities and found significant alterations in these receptors in $\mathrm{F} 1$ and F2 females. Oxytocin receptor binding was found to be elevated in the lateral septum, BNST, agranular insular cortex, and dorsal endopiriform nucleus of communally reared F1 females with a trend for the persistence of these elevations in the lateral septum of F2 females. Elevations in oxytocin receptor density have previously been demonstrated to be associated with increased maternal care and decreased anxiety-like behavior in rodents (Francis et al., 2000; Champagne and Meaney, 2007), suggesting that alterations in these neuropeptide receptors may account for the behavioral effects of communal rearing observed in F1 and F2 females. The oxytocin/ vasopressin system exhibits a high degree of plasticity in response to hormonal and experiential influences (Meddle et al., 2007; Curley et al., 2009). Previous studies have shown that elevated levels of maternal LG as well as exposure to juvenile social enrichment are associated with increased oxytocin receptors in both mothers and their female offspring (Francis et al., 2000, 2002; Champagne et al., 2001; Champagne and Meaney, 2007). Importantly, the magnitude of the influence of the juvenile social environment is dependent on the quality of care received in infancy. Thus offspring who received

\section{REFERENCES}

Agrell, J., Wolff, J. O., and Ylonen, H. (1998). Counter-strategies to infanticide in mammals: costs and consequences. Oikos 83, 507-517.

Anway, M. D., Cupp, A. S., Uzumcu, M., and Skinner, M. K. (2005). Epigenetic transgenerational actions of endocrine disruptors and male fertility. Science 308, 1466-1469.

Arai, J. A., Li, S., Hartley, D. M., and Feig, L. A. (2009). Transgenerational rescue of a genetic defect in long-term potentiation and memory formation

low levels of maternal LG do not display behavioral differences or changes in oxytocin receptor binding when exposed to social impoverishment but do show enhanced receptor binding, increased exploration of novelty and increased maternal care when exposed to social enrichment. These findings highlight the importance of considering individual differences in trait social and anxiety behavior when implementing early rearing manipulations. Though we observe significant "benefits" of communal rearing in Balb/c mice, these effects may be obscured when using a highly social and exploratory rodent strain.

F1 females reared in communal nests and F2 offspring of these females were found to have decreased V1a receptor binding in the lateral septum. Though previous research suggests that vasopressin and V1a receptors would facilitate social interactions (Landgraf et al., 2003; Bielsky et al., 2005a), increase maternal behavior (Bosch and Neumann, 2008; Nephew and Bridges, 2008b) and in some cases be associated with decreased anxiety-like behavior (Everts and Koolhaas, 1999), gene knockout, targeted viral vector and pharmacological studies would suggest that V1a receptor activity within the lateral septum is anxiogenic. V1a knockout mice have been demonstrated to exhibit increased open-arm entries on the elevated plus maze and decreased marble burring (Egashira et al., 2007) and site specific over-expression of the Vla receptor within the lateral septum is associated with decreased time spent in the light region of a light-dark box (Bielsky et al., 2005a). Infusion of a Vla antagonist into the septal region in rats has been found to increase open-arm entries in the elevated plus maze (Liebsch et al., 1996) and similar anxiolytic effects have been achieved through infusion of V1a receptor antisense (Landgraf et al., 1995). However, it should be noted that the anxiolytic effects of decreased V1a receptor levels/activity illustrated in previous studies are based primarily on effects is male rats and mice and the Vla receptor knockout has not been demonstrated to alter anxiety-like behavior in female mice (Bielsky et al., 2005b). It would appear likely that the impact of V1a receptor binding in the lateral septum for behavioral outcomes is sex-specific, species-specific and dependent on the context of neuropeptide levels within neural systems that interact with the septal region.

Overall, the communal nursing paradigm provides a novel and ethologically valid approach to the study of early social enrichment and here we provide evidence for the stability of the effects of these experiences within and across generations. These data have implications for understanding the pathways through which amelioration of deficits in reproductive and emotional behavior can be achieved.

\section{ACKNOWLEDGMENTS}

The authors wish to acknowledge funding received for this study from The Leverhulme Trust and Grant Number DP2OD001674 from the Office of the Director, National Institutes of Health.

by juvenile enrichment. J. Neurosci. 29 , 1496-1502.

Archer,J. (1973). Tests for emotionality in rats and mice: a review. Anim. Behav. 21, 205-235.

Badyaev,A.V., and Uller, T. (2009). Parental effects in ecology and evolution: mechanisms, processes and implications. Philos. Trans. R. Soc. Lond. 364, 1169-1177.

Belzung, C., and Griebel, G. (2001). Measuring normal and pathological anxiety-like behaviour in mice: a review. Behav. Brain Res. 125, 141-149. 
Benoit, D., and Parker, K. C. (1994). Stability and transmission of attachment across three generations. Child Dev. 65, 1444-1456.

Berman, C. (1990). Intergenerational transmission of maternal rejection rates among free-ranging rheus monkeys on Cayo Santiago. Anim. Behav. 44, 247-258.

Bielsky, I. F., Hu, S. B., Ren, X., Terwilliger, E. F., and Young, L. J. (2005a). The V1a vasopressin receptor is necessary and sufficient for normal social recognition: a gene replacement study. Neuron 47, 503-513.

Bielsky, I. F., Hu, S. B., and Young, L. J. (2005b). Sexual dimorphism in the vasopressin system: lack of an altered behavioral phenotype in female Vla receptor knockout mice. Behav. Brain Res. 164, 132-136.

Bosch,O.J., Meddle,S.L., Beiderbeck, D. I., Douglas, A. J., and Neumann, I. D. (2005). Brain oxytocin correlates with maternal aggression: link to anxiety. J. Neurosci. 25, 6807-6815.

Bosch, O. J., and Neumann, I. D. (2008). Brain vasopressin is an important regulator of maternal behavior independent of dams' trait anxiety. Proc. Natl. Acad. Sci. U.S.A. 105, 17139-17144.

Branchi, I. (2009). The mouse communal nest: investigating the epigenetic influences of the early social environment on brain and behavior development. Neurosci. Biobehav. Rev. 33, 551-559.

Branchi, I., and Alleva, E. (2006). Communal nesting, an early social enrichment, increases the adult anxiety-like response and shapes the role of social context in modulating the emotional behavior. Behav. Brain Res. 172, 299-306.

Branchi, I., D’Andrea, I., Fiore, M., Di Fausto, V., Aloe, L., and Alleva, E. (2006a). Early social enrichment shapes social behavior and nerve growth factor and brain-derived neurotrophic factor levels in the adult mouse brain. Biol. Psychiatry60, 690-696.

Branchi, I., D’Andrea, I., Sietzema, J., Fiore, M., Di Fausto, V., Aloe, L., and Alleva, E. (2006b). Early social enrichment augments adult hippocampal BDNF levels and survival of BrdUpositive cells while increasing anxiety- and "depression"-like behavior. J. Neurosci. Res. 83, 965-973.

Brodkin, E. S. (2007). BALB/c mice: low sociability and other phenotypes that may be relevant to autism. Behav. Brain Res. 176, 53-65.

Carola, V., Frazzetto, G., and Gross, C. (2006). Identifying interactions between genes and early environment in the mouse. Genes Brain Behav. 5, 189-199.
Champagne, F., Diorio, J., Sharma, S., and Meaney, M. J. (2001). Naturally occurring variations in maternal behavior in the rat are associated with differences in estrogen-inducible central oxytocin receptors. Proc. Natl. Acad. Sci. U.S.A. 98, 12736-12741.

Champagne, F., and Meaney, M. J. (2001). Like mother, like daughter: evidence for non-genomic transmission of parental behavior and stress responsivity. Prog. Brain Res. 133, 287-302.

Champagne, F. A. (2008). Epigenetic mechanisms and the transgenerational effects of maternal care. Front. Neuroendocrinol. 29, 386-397. doi: 10.1016/j.yfrne.2008.03.003.

Champagne, F. A., Curley, J. P., Keverne, E. B., and Bateson, P. P. (2007). Natural variations in postpartum maternal care in inbred and outbred mice. Physiol. Behav. 91, 325-334.

Champagne, F. A., Francis, D. D., Mar, A. and Meaney, M. J. (2003a). Variations in maternal care in the rat as a mediating influence for the effects of environment on development. Physiol. Behav. 79, 359-371.

Champagne, F. A., Weaver, I. C., Diorio, J., Sharma, S., and Meaney, M. J. (2003b). Natural variations in maternal care are associated with estrogen receptor alpha expression and estrogen sensitivity in the medial preoptic area. Endocrinology 144, 4720-4724.

Champagne,F.A., and Meaney,M.J.(2006) Stress during gestation alters postpartum maternal care and the development of the offspring in a rodent model. Biol. Psychiatry 59, 1227-1235.

Champagne, F. A., and Meaney, M. J. (2007). Transgenerational effects of social environment on variations in maternal care and behavioral response to novelty. Behav. Neurosci. 121, 1353-1363.

Champagne, F. A., Weaver, I. C., Diorio, J., Dymov, S., Szyf, M., and Meaney, M. J. (2006). Maternal care associated with methylation of the estrogen receptoralphalb promoter and estrogen receptor-alpha expression in the medial preoptic area of female offspring. Endocrinology 147, 2909-2915.

Chapman, D., and Scott, K. (2001). The impact of maternal intergenerational risk factors on adverse developmental outcomes. Dev. Rev. 21, 305-325.

Coutellier, L., Friedrich, A. C., Failing, K., Marashi, V., and Wurbel, H. (2009). Effects of foraging demand on maternal behaviour and adult offspring anxiety and stress response in C57BL/6 mice. Behav. Brain Res. 196, 192-199.

Coutellier, L., Friedrich, A. C., Failing, K., and Wurbel, H. (2008). Variations in the postnatal maternal environment in mice: effects on maternal behaviour and behavioural and endocrine responses in the adult offspring. Physiol. Behav. 93, 395-407.

Crawley, J. N. (1985). Exploratory behavior models of anxiety in mice. Neurosci. Biobehav. Rev. 9, 37-44.

Crews, D., Gore, A. C., Hsu, T. S. Dangleben, N. L., Spinetta, M. Schallert, T., Anway, M. D. and Skinner, M. K. (2007). Transgenerational epigenetic imprints on mate preference. Proc. Natl. Acad. Sci. U.S.A. 104, 5942-5946.

Crowcroft, P., and Rowe, F. P. (1963). Social organization and territorial behavior in the wild house mice ( $M u$ musculus L.). Proc. Zool. Soc. Lond. 140 517-531.

Curley, J. P., Champagne, F. A., Bateson, P. P., and Keverne, E. B. (2008). Transgenerational effects of impaired maternal care on behaviour of offspring and grandoffspring. Anim. Behav. 75, 1551-1561.

Curley, J. P., Jordan, E. R., Swaney, W. T. Izraelit, A., Kammel, S., and Champagne, F. A. (2009). The meaning of weaning: influence of the weaning period on behavioral development in mice. Dev. Neurosci. 31, 318-331.

D'Andrea, I., Alleva, E., and Branchi, I. (2007). Communal nesting, an early social enrichment, affects social competences but not learning and memory abilities at adulthood. Behav. Brain Res. 183, 60-66.

Egashira, N., Tanoue, A., Matsuda, T. Koushi, E., Harada, S., Takano, Y. Tsujimoto, G., Mishima, K., Iwasaki, K., and Fujiwara, M. (2007). Impaired social interaction and reduced anxiety-related behavior in vasopressin V1a receptor knockout mice. Behav. Brain Res. 178, 123-127.

Everts, H. G., and Koolhaas, J. M. (1999). Differential modulation of latera septal vasopressin receptor blockade in spatial learning, social recognition, and anxiety-related behaviors in rats. Behav. Brain Res. 99, 7-16.

Fairbanks, L. A. (1989). Early experience and cross-generational continuity of mother-infant contact in vervet monkeys. Dev. Psychobiol. 22, 669-681.

Fernandez-Teruel, A., Escorihuela, R. M. Castellano, B., Gonzalez, B., and Tobena, A. (1997). Neonatal handling and environmental enrichment effects on emotionality, novelty/reward seeking, and age-related cognitive and hippocampal impairments: focus on the Roman rat lines. Behav. Genet. 27, 513-526.

Francis, D. D., Champagne, F. C., and Meaney, M. J. (2000). Variations in maternal behaviour are associated with differences in oxytocin receptor levels in the rat. J. Neuroendocrinol. 12, 1145-1148.
Francis, D. D., Szegda, K., Campbell, G., Martin, W. D., and Insel, T. R. (2003). Epigenetic sources of behavioral differences in mice. Nat. Neurosci. 6 , 445-446.

Francis, D. D., Young, L. J., Meaney, M. J., and Insel, T. R. (2002). Naturally occurring differences in maternal care are associated with the expression of oxytocin and vasopressin (V1a) receptors: gender differences. J. Neuroendocrinol. 14, 349-353.

Frazier, C. R., Trainor, B. C., Cravens, C. J., Whitney, T. K., and Marler, C. A. (2006). Paternal behavior influences development of aggression and vasopressin expression in male California mouse offspring. Horm. Behav. 50, 699-707.

Insel, T. R., and Shapiro, L. E. (1992). Oxytocin receptor distribution reflects social organization in monogamous and polygamous voles. Proc. Natl. Acad. Sci. U.S.A. 89, 5981-5985.

Konig, B. (1994). Components of lifetime reproductive success in communally and solitarily nursing house mice: a laboratory study. Behav. Ecol. Sociobiol. 34, 275-283.

Landgraf, R., Frank, E., Aldag, J. M., Neumann, I. D., Sharer, C. A., Ren, X. Terwilliger, E. F., Niwa, M., Wigger, A., and Young, L. J. (2003). Viral vectormediated gene transfer of the vole $\mathrm{Vla}$ vasopressin receptor in the rat septum: improved social discrimination and active social behaviour. Eur. J. Neurosci. 18, 403-411.

Landgraf, R., Gerstberger, R., Montkowski, A., Probst, J. C., Wotjak, C. T., Holsboer, F., and Engelmann, M. (1995).V1 vasopressin receptor antisense oligodeoxynucleotide into septum reduces vasopressin binding, social discrimination abilities, and anxiety-related behavior in rats. J. Neurosci. 15, 4250-4258.

Leckman, J. F., and Herman, A. E. (2002). Maternal behavior and developmental psychopathology. Biol. Psychiatry 51, 27-43.

Lehmann, J., and Feldon, J. (2000). Longterm biobehavioral effects of maternal separation in the rat: consistent or confusing? Rev. Neurosci. 11, 383-408.

Li, Y.-F., Langholz, B., Salam, M. T., and Gilliland, F. D. (2005). Maternal and grandmaternal smoking patterns are associated with early childhood asthma. Chest 127, 1232-1241.

Liebsch, G., Wotjak, C. T., Landgraf, R., and Engelmann, M. (1996). Septal vasopressin modulates anxiety-related behaviour in rats. Neurosci. Lett. 217, 101-104.

Lonstein, J.S. (2005). Resolving apparent contradictions concerning the relationships among fear or anxiety and aggression during lactation: theoretical 
comment on D'Anna, Stevenson, and Gammie (2005). Behav. Neurosci. 119 , 1165-1168.

Lovic, V., Gonzalez, A., and Fleming, A. S. (2001). Maternally separated rats show deficits in maternal care in adulthood. Dev. Psychobiol. 39, 19-33.

Maestripieri, D. (2005). Early experience affects the intergenerational transmission of infant abuse in rhesus monkeys. Proc. Natl. Acad. Sci. U.S.A. 102, 9726-9729.

Maestripieri, D., and D'Amato, F. R. (1991). Anxiety and maternal aggression in house mice (Mus musculus): a look at interindividual variability. J. Comp. Psychol. 105, 295-301.

Manning, C. J., Wakeland, E. K., and Potts, W. K. (1992). Communal nesting patterns in mice implicate $\mathrm{MHC}$ genes in kin recognition. Nature 360, 581-583.

McCarthy, M. M., Besmer, H. R., Jacobs, S. C., Keidan, G. M., and Gibbs, R. B. (1997). Influence of maternal grooming, sex and age on Fos immunoreactivity in the preoptic area of neonatal rats: implications for sexual differentiation. Dev. Neurosci. 19, 488-496.

Meaney, M. J. (2001). Maternal care, gene expression, and the transmission of individual differences in stress reactivity across generations. Annu. Rev. Neurosci. 24, 1161-1192.

Meddle, S. L., Bishop, V. R., Gkoumassi, E., van Leeuwen, F. W., and Douglas, A. J. (2007). Dynamic changes in oxytocin receptor expression and activation at parturition in the rat brain. Endocrinology 148, 5095-5104.

Melo, A. I., Hernandez-Curiel, M., and Hoffman, K. L. (2009). Maternal and peer contact during the postnatal period participate in the normal development of maternal aggression, maternal behavior, and the behavioral response to novelty. Behav. Brain Res. 201, 14-21.

Mennella, A. M., Blumberg, M. S., McCiintock, M. K., and Moltz, H. (1990). Inter-litter competition and communal nursing among Norway rats: advantages of birth synchrony. Behav. Ecol. Sociobiol. 27, 183-190.

Mueller, B. R., and Bale, T. L. (2007). Early prenatal stress impact on coping strat- egies and learning performance is sex dependent. Physiol. Behav. 91, 55-65.

Mueller, B. R., and Bale, T. L. (2008). Sexspecific programming of offspring emotionality after stress early in pregnancy. J. Neurosci. 28, 9055-9065.

Nephew, B. C., and Bridges, R. S. (2008a). Arginine vasopressin V1a receptor antagonist impairs maternal memory in rats. Physiol. Behav. 95, 182-186.

Nephew, B. C., and Bridges, R. S. (2008b). Central actions of arginine vasopressin and a V1a receptor antagonist on maternal aggression, maternal behavior, and grooming in lactating rats. Pharmacol. Biochem. Behav. 91, 77-83.

Newbold, R. R., Padilla-Banks, E., and Jefferson, W.N. (2006). Adverse effects of the model environmental estrogen diethylstilbestrol are transmitted to subsequent generations. Endocrinology 147, S11-S17.

Panksepp, J. B., and Lahvis, G. P. (2007). Social reward among juvenile mice. Genes Brain Behav. 6, 661-671.

Park, M. K., Hoang, T. A., Belluzzi, J. D., and Leslie, F. M. (2003). Gender specific effect of neonatal handling on stress reactivity of adolescent rats. J. Neuroendocrinol. 15, 289-295.

Pauk, J., Kuhn, C. M., Field, T. M., and Schanberg, S. M. (1986). Positive effects of tactile versus kinesthetic or vestibular stimulation on neuroendocrine and ODC activity in maternally-deprived rat pups. Life Sci. 39, 2081-2087.

Paxinos, G., and Franklin, K. B. J. (2003). The Mouse Brain in Stereotaxic Coordinates, 2nd edn. New York, Academic Press.

Priebe, K., Romeo, R. D., Francis, D. D., Sisti, H. M., Mueller, A., McEwen, B. S., and Brake, W. G. (2005). Maternal influences on adult stress and anxiety-like behavior in C57BL/6J and BALB/cJ mice: a cross-fostering study. Dev. Psychobiol. 47, 398-407.

Rosenblum, L.A., and Paully, G.S. (1984). The effects of varying environmental demands on maternal and infant behavior. Child Dev. 55, 305-314.

Roth, T. L., Lubin, F. D., Funk, A. J., and Sweatt, J. D. (2009). Lasting epigenetic influence of early-life adversity on the BDNF Gene. Biol. Psychiatry. 65, 760-769.

Roy, V., Merali, Z., Poulter, M. O., and Anisman, H. (2007). Anxiety responses, plasma corticosterone and central monoamine variations elicited by stressors in reactive and nonreactive mice and their reciprocal F1 hybrids. Behav. Brain Res. 185, 49-58.

Russell, A. F., and Lummaa, V. (2009) Maternal effects in cooperative breeders: from hymenopterans to humans. Philos. Trans. R. Soc. Lond. 364, 1143-1167.

Sayler, A., and Salmon, M. (1969). Communal nursing in mice: influence of multiple mothers on the growth of the young. Science 164, 1309-1310.

Sayler, A., and Salmon, M. (1971).An ethological analysis of communal nursing of the house mouse (Mus musculus). Behaviour 40, 62-85.

Schultz, L. A., and Lore, R. K. (1993). Communal reproductive success in rats (Rattus norvegicus): effects of group composition and prior social experience. J. Comp. Psychol. 107, 216-222.

Slotten, H. A., Kalinichev, M., Hagan, J. J. Marsden, C.A., and Fone, K. C. (2006). Long-lasting changes in behavioural and neuroendocrine indices in the rat following neonatal maternal separation: gender-dependent effects. Brain Res. 1097, 123-132.

Smith,J.W.,Seckl,J.R.,Evans,A. T.,Costall, B. and Smythe, J. W. (2004). Gestational stress induces post-partum depressionlike behaviour and alters maternal care in rats. Psychoneuroendocrinology 29, 227-244.

Svare, B. (ed.) (1990). Maternal Aggression: Hormonal, Genetic, and Developmental Determinants. New York, Oxford University Press.

Svare, B., Betteridge, C., Katz, D., and Samuels, O. (1981). Some situational and experiential determinants of maternal aggression in mice. Physiol. Behav. 26, 253-258.

Uvnas-Moberg, K. (1997). Physiological and endocrine effects of social contact. Ann. N. Y. Acad. Sci. 807, 146-163.

van Praag, H., Kempermann, G., and Gage, F. H. (2000). Neural consequences of environmental enrichment. Nat. Rev. 1, 191-198.
Veenema, A. H., Bredewold, R., and Neumann, I. D. (2007). Opposite effects of maternal separation on intermale and maternal aggression in C57BL/6 mice: link to hypothalamic vasopressin and oxytocin immunoreactivity. Psychoneuroendocrinology 32, 437-450.

Veenema, A. H., and Neumann, I. D. (2008). Central vasopressin and oxytocin release: regulation of complex social behaviours. Prog. Brain Res. 170, 261-276.

Wakshlak, A., and Weinstock, M. (1990). Neonatal handling reverses behavioral abnormalities induced in rats by prenatal stress. Physiol. Behav. 48, 289-292.

Weinberg, J., Kim, C. K., and Yu, W. (1995). Early handling can attenuate adverse effects of fetal ethanol exposure. Alcohol 12, 317-327.

Zambrano, E., Martinez-Samayoa, P. M., Bautista, C. J., Deas, M., Guillen, L., Rodriguez-Gonzalez, G. L., Guzmán, C., Larrea, F., and Nathanielsz, P. W. (2005). Sex differences in transgenerational alterations of growth and metabolism in progeny (F2) of female offspring (F1) of rats fed a low protein diet during pregnancy and lactation. J. Physiol. 566, 225-236.

Conflict of Interests Statement: The authors confirm that they have no conflicts of interests.

Received: 30 June 2009; paper pending published: 21 July 2009; accepted: 19 August 2009; published online: 15 September 2009.

Citation: Curley JP, Davidson S, Bateson P and Champagne FA (2009) Social enrichment during postnatal development induces transgenerational effects on emotional and reproductive behavior in mice. Front. Behav. Neurosci. 3:25. doi: 10.3389/neuro.08.025.2009

Copyright (c) 2009 Curley, Davidson, Bateson and Champagne. This is an open-access article subject to an exclusive license agreement between the authors and the Frontiers Research Foundation, which permits unrestricted use, distribution, and reproduction in any medium, provided the original authors and source are credited. 